\title{
Assessing the ability of three land ecosystem models to simulate gross carbon uptake of forests from boreal to Mediterranean climate in Europe
}

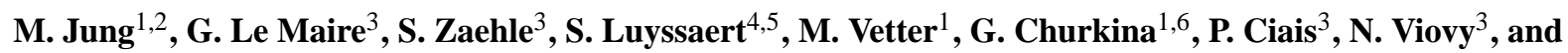 \\ M. Reichstein ${ }^{1}$ \\ ${ }^{1}$ Max Planck Institute for Biogeochemistry, Jena, Germany \\ ${ }^{2}$ International Max Planck Research School on Earth System Modelling, Hamburg, Germany \\ ${ }^{3}$ Laboratory for Climate Sciences and the Environment (LSCE), Joint Unit of CEA-CNRS, Gif-sur-Yvette, France \\ ${ }^{4}$ Department of Biology, University of Antwerp, Universiteitsplein 1, B-2610 Wilrijk, Belgium \\ ${ }^{5}$ College of Forestry, Oregon State University, Corvallis, OR 97331-5752 USA \\ ${ }^{6}$ School of Natural Resources and Environment, University of Michigan, Ann Arbor, USA
}

Received: 28 March 2007 - Published in Biogeosciences Discuss.: 26 April 2007

Revised: 26 July 2007 - Accepted: 9 August 2007 - Published: 14 August 2007

\begin{abstract}
Three terrestrial biosphere models (LPJ, Orchidee, Biome-BGC) were evaluated with respect to their ability to simulate large-scale climate related trends in gross primary production (GPP) across European forests. Simulated GPP and leaf area index (LAI) were compared with GPP estimates based on flux separated eddy covariance measurements of net ecosystem exchange and LAI measurements along a temperature gradient ranging from the boreal to the Mediterranean region. The three models capture qualitatively the pattern suggested by the site data: an increase in GPP from boreal to temperate and a subsequent decline from temperate to Mediterranean climates. The models consistently predict higher GPP for boreal and lower GPP for Mediterranean forests. Based on a decomposition of GPP into absorbed photosynthetic active radiation (APAR) and radiation use efficiency (RUE), the overestimation of GPP for the boreal coniferous forests appears to be primarily related to too high simulated LAI - and thus light absorption (APAR) - rather than too high radiation use efficiency. We cannot attribute the tendency of the models to underestimate GPP in the water limited region to model structural deficiencies with confidence. A likely dry bias of the input meteorological data in southern Europe may create this pattern.

On average, the models compare similarly well to the site GPP data (RMSE of $\sim 30 \%$ or $420 \mathrm{gC} / \mathrm{m} 2 / \mathrm{yr}$ ) but differences are apparent for different ecosystem types. In terms of absolute values, we find the agreement between site based GPP estimates and simulations acceptable when we consider uncertainties about the accuracy in model drivers, a potential representation bias of the eddy covariance sites, and uncer-

Correspondence to: M. Jung

(mjung@bgc-jena.mpg.de)
\end{abstract}

tainties related to the method of deriving GPP from eddy covariance measurements data. Continental to global datamodel comparison studies should be fostered in the future since they are necessary to identify consistent model bias along environmental gradients.

\section{Introduction}

Continental to global scale simulations of the land carbon cycle are subject to uncertainties related to model structure, parameters, and input driver data (McGuire et al., 2001; Moorcroft, 2006; Morales et al., 2005; Zaehle et al., 2005). Confronting simulations with measurements allows assessing the model's performance, gaining confidence in the model predictions and/or identify major issues with the model structure. Such comparisons have been repeatedly made for single or few intensively investigated eddy covariance flux measurement sites when it was possible to parameterise and drive the models with in-situ data (e.g. Churkina et al., 2003; Kucharik et al., 2006; Morales et al., 2005). These analyses revealed important insights regarding the credibility of the model's dynamics and simulated temporal variations. However, models designed for the continental to global scale should also be evaluated on that scale, i.e. investigating how well the broad patterns along large environmental gradients are reproduced. Such studies have rarely been presented, primarily due to a lack of consistent synthesis work of carbon flux measurements. Global data for net primary productivity (NPP) are available (Scurlock et al., 1999, http://www-eosdis.ornl.gov/NPP/npp_home.html) but prove to be difficult to use as benchmarks (e.g. Cramer et

Published by Copernicus Publications on behalf of the European Geosciences Union. 


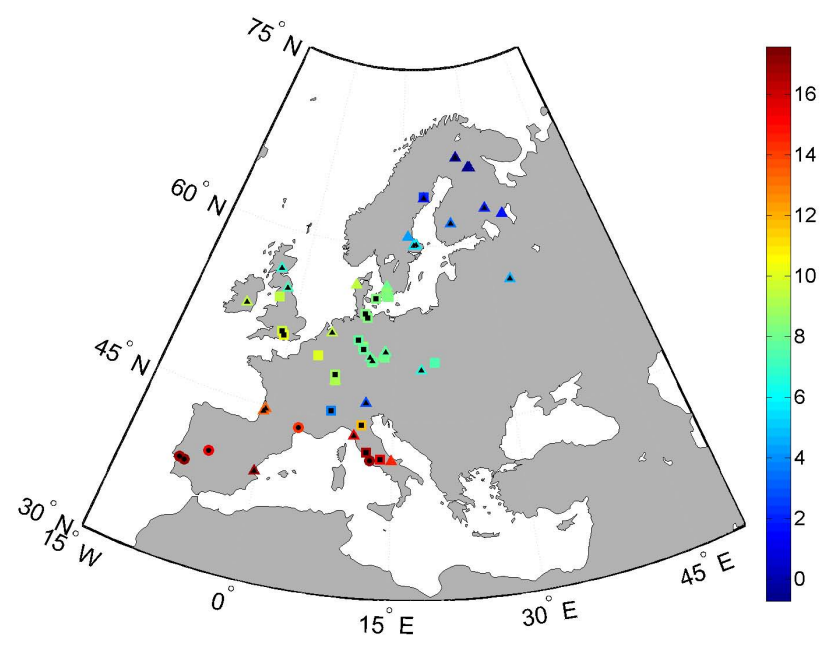

Fig. 1. Spatial distribution of GPP and LAI measurements. Sites with GPP measurements have a black filling. Triangles: evergreen needleleaf forests, squares: deciduous broadleaf forests, circles: evergreen broadleaf forests. Colour represents mean annual temperature in ${ }^{\circ} \mathrm{C}$ (1981-2000 mean from REMO).

al., 1999; Zaehle et al., 2005). Because compilations of NPP measurements suffer from inconsistent methodologies, individual values from different sites and investigators are often not compatible (but see Luyssaert et al., 2007). In addition, NPP data are known to be biased low to an unknown extent and there is strong indication that this bias can change substantially for different climate regions (Luyssaert et al., 2007).

Consistent estimates of gross primary production (GPP) are now becoming available from the eddy covariance measurement community based on methods that separate measured net ecosystem exchange (NEE) into GPP and ecosystem respiration (Reichstein et al., 2005). In this study we evaluate simulated GPP from three global biogeochemical models (LPJ, Orchidee, Biome-BGC) for forest ecosystems in Europe. Our study is consistent with, and complements a recent model intercomparison project within the Carboeurope-IP project that aims to understand, quantify, and reduce uncertainties of the European carbon budget (http://www.carboeurope.org/). We investigate the performance of the models to reproduce the broad pattern suggested by eddy covariance based GPP along a mean annual temperature gradient running from the boreal to the Mediterranean. We evaluate to what extent we can be confident with European scale simulations of forest GPP, and aim to identify consistent patterns of correspondence and mismatch with the data. We further propose a simple method of decomposing GPP into APAR and RUE that aids in the diagnoses of model performance using ancillary leaf area index (LAI) measurements.

\section{Materials and methods}

\subsection{Site data}

The observational site data we use originate from the recent data compilation of Luyssaert et al. (2007). We extracted all available data from sites with GPP (annual sums) or LAI measurements (annual maximum) for Europe. We excluded sites from mixed forests (mixed plant functional types or PFTs), manipulative experiments where the forest was fertilized or irrigated, as well as recently disturbed plots and clear cuts. Finally, 37 and 47 sites for GPP and LAI respectively are available of which 22 have both GPP and LAI estimates (Fig. 1).

The GPP data originate from Carboeurope eddy covariance tower sites that measure the net ecosystem $\mathrm{CO}_{2}$ exchange (NEE). The data represent the time period from approximately 1996 to 2005 with a bias towards recent times. The NEE fluxes had been separated into GPP and ecosystem respiration $\left(\mathrm{R}_{\mathrm{eco}}\right.$ ) by subtracting $\mathrm{R}_{\mathrm{eco}}$. $\mathrm{R}_{\mathrm{eco}}$ had been calculated based on its night time temperature sensitivities, the vast majority according to Reichstein et al. (2005).

LAI measurements are partly based on different methods; indirect optical methods have been used primarily. By means of the Lambert-Beer's law, we converted LAI to the fraction of absorbed photosynthetic active radiation (fAPAR) which is the key variable for light absorption and thus GPP (Eq. 1). The transformation of LAI to fAPAR allows a better interpretation to what extent a simulated mismatch in light harvesting might be responsible for the mismatch of simulated and observed GPP since light transmission is a negative exponential function of LAI. The Lambert-Beer's law as 1-D representation of canopy radiation transfer is also used in the three models to estimate light extinction.

$\mathrm{fAPAR}=1-e^{-k \times \mathrm{LAI}}$

where $k$ denotes the light extinction coefficient, assuming $k=0.5$ for conifers and $k=0.58$ for broadleaf trees. The conversion of LAI to fAPAR implies larger discrepancy of light harvesting at low LAI values and smaller discrepancy at high LAI values. For example, the fAPAR difference between LAIs of 2 (fAPAR $\sim 0.63$ ) and 4 (fAPAR 0.86) is much larger than between LAIs of 6 (fAPAR 0.95 ) and 8 (fAPAR 0.98). While LAI can be considered to be a determinant of GPP in the range of 0 to 4 it becomes more a consequence of GPP beyond an LAI of 4 when changes of LAI have only minor effects on light absorption.

\subsection{Model simulations}

We performed simulations at the locations of the measurement sites using three state of the art global biogeochemical models: LPJ, Orchidee, and Biome-BGC. The models are described in detail in Sitch et al. (2003), Krinner et al. (2005), and Thornton $(1998,2002)$, respectively. We used the same 
input data for each model, according to a modelling protocol that is consistent with model intercomparison studies by Vetter et al. (2007) and Jung et al. (2007)in review to ensure comparability. We prescribed the PFT according to the prevailing vegetation type given in the database by Luyssaert et al. (2007). No site history was prescribed that accounts for age and management related effects; the models simulate mature forest stands. Soil water holding capacity and meteorological model drivers originate from gridded data sets with a spatial resolution of $0.25^{\circ}$. Water holding capacity data are based on IGBP-DIS, 2000 soil texture data. Meteorological model input from 1958-2005 is from a regional climate model (REMO, Jacob and Podzun, 1997) that was driven with NCEP reanalysis (Kalnay et al., 1996) at the boundaries of the European model domain (Feser et al., 2001). Details about model drivers and the modelling protocol are available in Vetter et al. (2007) and the CarboeuropeIP model intercomparison homepage (http://www.bgc-jena. mpg.de/bgc-systems/projects/ce_i/index.shtml).

For consistency, we matched simulated GPP and LAI with the site data on a site by site and year by year basis. Subsequently, the yearly data were aggregated (averaged) to the site level. In cases two or more measurement sites with the same PFT fell within the same $0.25^{\circ}$ gridcell (i.e. identical model output), data on site level were further averaged to gain more representative values on the $0.25^{\circ}$ gridcell level.

\subsection{Decomposing GPP into APAR and RUE}

We decomposed GPP [ $\mathrm{gC} \mathrm{m}^{-2} \mathrm{yr}^{-1}$ ] into absorbed photosynthetic active radiation (APAR [MJ ${ }^{-2} \mathrm{yr}^{-1}$ ) and radiation use efficiency (RUE $\left[\mathrm{gC} \mathrm{MJ}^{-1}\right]$ ). This procedure provides further information about possible causes of mismatch between simulated and site eddy covariance based GPP.

$\mathrm{GPP}=\mathrm{APAR} \times \mathrm{RUE}$

We calculate APAR for the models according to a standard method used in model intercomparisons from monthly mean leaf area index and radiation (e.g. Bondeau et al., 1999; Ruimy et al., 1999) (Eq. 3). For the actual forest, there is commonly only one annual LAI measurements that represents approximately the annual maximum. In order estimate APAR for the forest sites we use the simulated seasonal pattern of fAPAR from the models but scale the simulated maximum fAPAR to the measured fAPAR (both calculated from LAI). In this way we calculate the APAR of the forest sites by using the modelled leaf phenology but correct for the wrong magnitude of modelled fAPAR. Our approach yields consistent estimates of APAR for the simulated and actual forest that allows comparison among them.

$\mathrm{APAR}=\sum_{m=1}^{12} \mathrm{fAPAR}_{\text {sim } m} \times \mathrm{PAR}_{m}[\times C F]$ with

$C F=\frac{\text { fAPAR }_{\text {obs }}}{\text { fAPAR }_{\max } \text { sim }}$

Where, APAR denotes the absorbed photosynthetic active radiation $\left[\mathrm{MJ} \mathrm{m}^{-2} \mathrm{yr}^{-1}\right], \mathrm{m}$ is an index for the month, fAPAR is the fraction of absorbed photosynthetic active radiation, calculated according to Eq. (1), the subscript sim denotes the simulation, PAR is photosynthetic active radiation $\left[\mathrm{MJ} \mathrm{m}^{-2}\right.$ month $^{-1}$ ] from REMO, assuming PAR $=0.48 \times$ global (short wave) radiation. $\mathrm{CF}$ is a correction factor that was only used for the estimation of APAR at the actual forest sites based on one LAI measurement.

The calculation is performed for all years with GPP measurements with subsequent averaging over the years. Since the seasonal pattern of simulated fAPAR (leaf phenology) may differ among models we calculate an actual site APAR for each model. The differences between the site APARs for different models are then entirely related to differently simulated phenology not due to the maximum reached LAI. Site and modelled RUE can now be calculated based on Equation 2, i.e. using eddy covariance flux separated GPP and site APAR, and simulated GPP and simulated APAR respectively.

Our method to decompose GPP into APAR and RUE for both, simulated and actual forest ecosystems uses several necessary simplifications and is only a first order approximation. We do not account for factors like albedo, diffuse radiation, and complex canopy structure that are relevant to the realistic estimations of fAPAR from LAI. Moreover, the models use internally partly different representations of the energy budget (e.g. albedo), differ slightly in the PFT specific light extinction coefficients and assumptions about upscaling of light absorption from tree to grid cell level. The derived absolute values of APAR and RUE are neither comparable among models nor to field measurements. However, our approach yields consistent results for APAR and RUE between simulated and actual forest ecosystem, since we apply the same method. It is an efficient way of assessing whether systematic differences of light harvesting can explain the mismatch between observed and modelled GPP. A drawback of the method is that it does not account for the observed seasonal pattern of light absorption due to a lack of measurement data with high temporal resolution. Consequently, we rely on the modelled seasonal pattern of LAI. Using the simulated seasonal pattern of LAI is only a minor issue for evergreen coniferous forests and we therefore restrict the application of the decomposition method to coniferous forests. Using the method for deciduous vegetation would require a priori confidence in the simulated timing of leaf onset, maximum LAI and leaf senescence for all three models. Alternatively, the availability of seasonally resolved measurements of LAI and/or of light interception for many sites would make it possible to use the actual observed seasonal cycle of leaf phenology. 

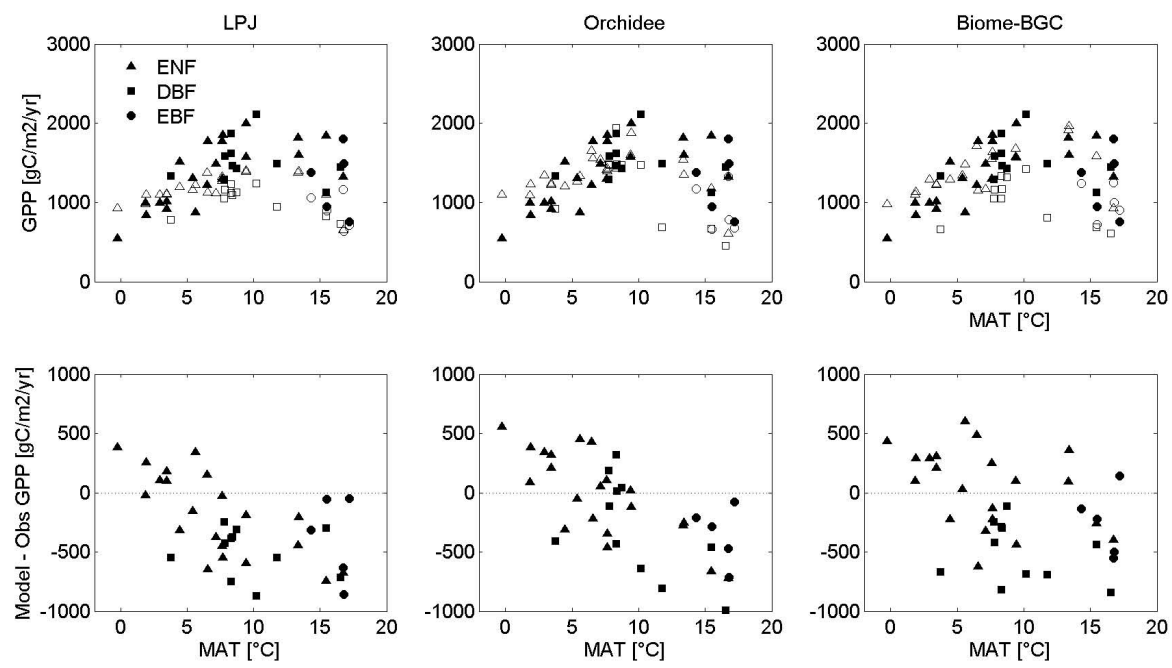

Fig. 2. Top panel: eddy covariance flux separated (filled markers) and modelled (open markers) GPP along the mean annual temperature gradient across Europe. Bottom panel: difference between modelled and eddy covariance flux separated GPP along mean annual temperature (MAT, 1981-2000 mean based on the REMO data set). ENF: evergreen needleleaf forests, DBF: deciduous broadleaf forests, EBF: evergreen broadleaf forests.

Table 1. Relative RMSE and mean eddy covariance flux separated and modelled GPP, stratified by forest ecosystem type. The relative RMSE is calculated as RMSE divided by the mean of the eddy covariance flux separated GPP values.

\begin{tabular}{|c|c|c|c|c|c|c|c|c|}
\hline \multirow[t]{2}{*}{ Forest ecosystem type } & \multirow{2}{*}{$\begin{array}{l}\text { Number } \\
\text { of sites }\end{array}$} & \multicolumn{4}{|c|}{ Mean GPP [gC/m2/yr] } & \multicolumn{3}{|c|}{ Relative RMSE [\%] } \\
\hline & & Observed & LPJ & Orchidee & $\begin{array}{l}\text { Biome- } \\
\text { BGC }\end{array}$ & LPJ & Orchidee & $\begin{array}{l}\text { Biome- } \\
\text { BGC }\end{array}$ \\
\hline All & 37 & 1400 & 1097 & 1252 & 1243 & 32.34 & 29.56 & 29.65 \\
\hline Boreal evergreen needleleaf & 9 & 1003 & 1102 & 1225 & 1232 & 23.65 & 33.80 & 31.95 \\
\hline Temperate evergreen needleleaf & 10 & 1643 & 1311 & 1537 & 1600 & 25.12 & 16.43 & 21.08 \\
\hline Temperate deciduous broadleaf & 10 & 1534 & 1060 & 1305 & 1067 & 33.35 & 27.41 & 33.75 \\
\hline Mediterranean evergreen needleleaf & 2 & 1586 & 879 & 894 & 1259 & 44.61 & 43.65 & 21.08 \\
\hline Mediterranean deciduous broadleaf & 2 & 1197 & 811 & 558 & 665 & 42.35 & 60.84 & 51.32 \\
\hline $\begin{array}{l}\text { Mediterranean evergreen broadleaf } \\
\text { forest }\end{array}$ & 4 & 1358 & 893 & 989 & 1097 & 41.03 & 32.59 & 28.29 \\
\hline
\end{tabular}

\section{Results and discussion}

\subsection{Gross primary productivity}

LPJ, Orchidee, and Biome-BGC reproduce the general pattern of GPP changes along the temperature (MAT) gradient across Europe. Across the continent GPP increase from boreal to temperate and subsequently decreases from temperate to Mediterranean regions (Fig. 2). However, the models consistently predict higher GPP for the boreal and lower GPP for the Mediterranean zone than suggested by eddy covariance based GPP. Variations of GPP by the LPJ model are smaller than indicated by eddy covariance based GPP and the other two models Orchidee, and Biome-BGC. By comparing the means of observed and modelled GPP over all sites, we find that all the three models predict on average lower GPP than the eddy covariance based (Table 1), while the difference between simulated and observed means is not significant for Orchidee and Biome-BGC (according to a one-way analysis of variance (ANOVA)).

The root mean square error of prediction (RMSE) over all sites is in the order of $420 \mathrm{gC} / \mathrm{m} 2 / \mathrm{yr}(\sim 30 \%)$ for the three models (Table 1). The stratification by ecosystem types reveals differences among models as well as among forest types and reveals individual contributions to the overall RMSE. On average, the RMSE is smallest for temperate coniferous sites (16-25\%) and largest for Mediterranean forest ecosystems (21-61\%), which has also been observed 
by Morales et al. (2005) with respect to monthly simulations of net ecosystem exchange and evapotranspiration from Orchidee, LPJ-GUESS, and RHESSyS (Biome-BGC is part of RHESSyS). LPJ, Orchidee, and Biome-BGC consistently predict higher GPP for the boreal forest by 10 to $23 \%$, lower GPP for temperate deciduous broadleaf forest and Mediterranean sites by 15 to $31 \%$ and 21 to $45 \%$ respectively. Between the models, LPJ is closest regarding the boreal forests (RMSE of 24\%), Orchidee for temperate sites (RMSE of 16 and $27 \%$ for conifers and broadleaves respectively), and Biome-BGC for Mediterranean evergreens (RMSE of 21 and $28 \%$ for conifers and broadleaves respectively). The latter statement is somewhat ambiguous, given the small number of data points in the Mediterranean.

Declining GPP towards the Mediterranean region is primarily related to increasing dryness. Reichstein et al. (2007) found that GPP of forest ecosystems south of $52^{\circ}$ latitude in Europe scales approximately linear with an index of water availability (IWA) which is defined as the ratio of actual to potential evapotranspiration. We find no systematic pattern of changes of the difference between simulated and eddy covariance based GPP along the gradient of water availability for this region, except that all three models tend to underestimate GPP (Fig. 3). Underestimation of GPP in the water limited part of Europe suggests that the models do not simulate the soil moisture conditions appropriately (e.g. due to overestimation of evaporation and or transpiration) or are too sensitive to variations of soil moisture. However, we cannot rule out the effect of uncertain model input data. The Mediterranean is a very heterogeneous landscape and moisture conditions resulting from localised rainfall and local soil characteristics may deviate substantially from the rather coarse driver data. There is further indication that the meteorological data from REMO are biased towards too dry conditions. The REMO data show on average larger vapour pressure deficit and lower precipitation in southern Europe in comparison to an alternative meteorological dataset from ECMWF, which impacts strongly on simulations of GPP from BiomeBGC (Jung et al., 2007).

Consistent with results of Morales et al. (2005), the discrepancy between simulations and reference data is higher for deciduous than for evergreen forests. The model's capacity to simulate the phenology of deciduous trees is therefore a likely factor that causes larger deviations for deciduous forests. Phenology involves several aspects relevant to carbon assimilation. The timing of budburst and leaf senescence determines the length of the growing season and together with the seasonal course of fAPAR the amount of light that can be harvested. Depending on the meteorological conditions, the timing of the onset of photosynthesis and thus transpiration may further impact on the efficiency to assimilate carbon later in the season due to the continuing depletion of available soil water. Beyond the seasonal course of LAI there is an internal "physiological" phenology of leaf properties such as leaf nitrogen concentration and chloro- phyll content that control photosynthetic capacity. Orchidee is the only model among the three considered in this study that accounts for such indirect effects using a dependence of maximum photosynthetic capacity on leaf age, which may explain why Orchidee performs better for temperate deciduous forests. A systematic test of the model's ability to simulate effects of phenology on photosynthesis at different sites as well as separating the relevance of different factors involved is challenging but needed for the future. Such study would require substantially more information of the forest ecosystem, including daily measurements of light absorbtion in the canopy, and model simulations with daily output that are forced by in-situ measured meteorological and soil data.

Our primary goal is to assess the general correspondence of European scale simulations and eddy covariance based GPP along the MAT gradient. Thus we used the same driver data as previous modelling studies of Carboeurope-IP (Jung et al., 2007; Vetter et al., 2007). This approach has the advantage that model evaluation is facilitated at their scale of application, i.e. continental to global including all uncertainties involved in large scale modelling. However, it trades-off to some extent with the identification of model structural uncertainties and unambiguous identification of which model performs best since input data effects can not be separated. Substantial deviation between the rather coarse soil and meteo input data and in situ conditions at the measurement sites can be expected due to small scale variability (esp. convective rainfall, cloudiness, soil structure and depth) and general uncertainties regarding the quality of the coarse scale model input. Considering input data effects and uncertainties of the GPP estimates from Carboeurope sites, the absolute simulated GPP values may be considered to be in the range of the uncertainty of our approach. Complementary, to this extensive data-model comparison study that covers well large climate gradients of Europe, we are currently undertaking effort to better understand real and model world controls of GPP variations for a few selected sites using in-situ measured model driver data.

\subsection{Leaf area index}

In this section we compare simulated maximum LAI with measurements in order to gain more insight in the model performances and what may cause some of the consistent discrepancy between eddy covariance based and modelled GPP particularly along the gradient from boreal to temperate climate. LPJ and Orchidee simulate hardly any changes of LAI (expressed as fAPAR, see section 2.1) from the boreal to the temperate zone which results in substantial overestimation of fAPAR in the boreal zone but reasonable agreement for temperate forests (Fig. 4). Biome-BGC captures the pattern qualitatively and does simulate an increase of LAI from boreal to temperate but not as strong as suggested by the measurements. The simulated LAI of boreal conifers is still too high while LAI of temperate conifers appears too 

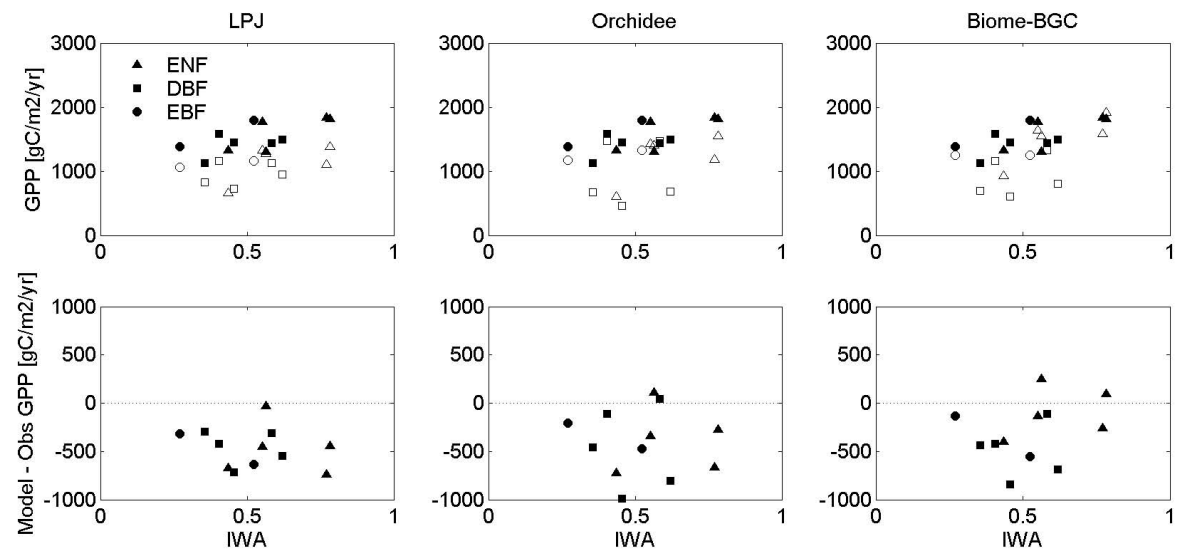

Fig. 3. Top panel: eddy covariance flux separated (filled markers) and modelled (open markers) GPP along a gradient of water availability for sites south of $52^{\circ}$ latitude. The index of water availability (IWA) is calculated as the ratio of actual to potential evapotranspiration and is based on measurements from the flux towers (see Reichstein et al., 2007 for details). Bottom panel: difference between modelled and eddy covariance flux separated GPP along the gradient of water availability. ENF: evergreen needleleaf forests, DBF: deciduous broadleaf forests, EBF: evergreen broadleaf forests.
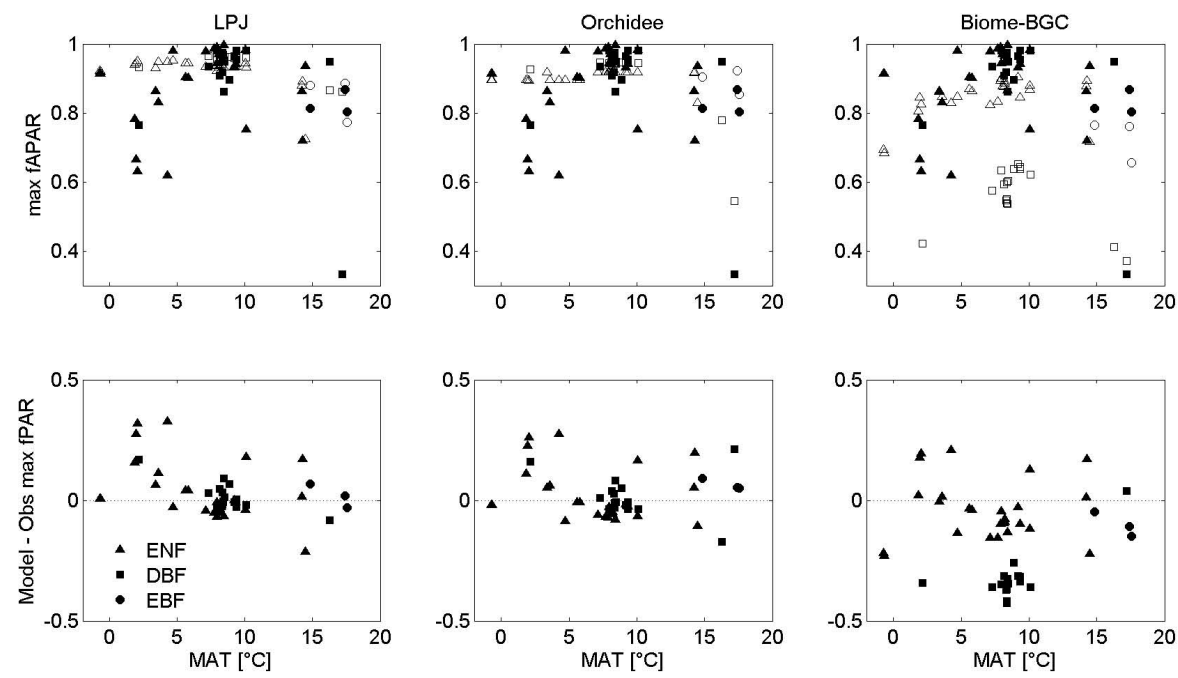

Fig. 4. Top panel: observed (filled markers) and modelled (open markers) maximum fAPAR along the mean annual temperature gradient across Europe. Bottom panel: difference between modelled and observed fAPAR along MAT. ENF: evergreen needlleaf forests, DBF: deciduous broadleaf forests, EBF: evergreen broadleaf forests.

low. In addition, deciduous forests exhibit far too low leaf area in Biome-BGC. The measurements and all three models suggest decreasing LAI when moving from temperate to Mediterranean climate.

Leaf area is constrained by the availability of resources (Cowling and Field, 2003). In LPJ and Orchidee, the main resource limitation is plant available water while BiomeBGC includes nitrogen limitation. In a global NPP model intercomparison, Bondeau et al. (1999) suggested that models that include only water limitation tend to overestimate light harvesting when nitrogen limitation is present. The boreal zone is known to be nitrogen limited and this limitation de- creases as nitrogen availability increases towards the temperate zone due to higher turnover but also anthropogenic deposition. The lack of an explicit nitrogen cycle may cause that LPJ and Orchidee do not simulate increasing LAI from boreal to temperate. On the other hand, the observed increase of LAI from boreal to temperate is partly an effect of a change in the prevailing conifer species from pine to spruce the latter being known to exhibit very high LAI (e.g. Breda, 2003) while global models cannot account for such species related effects. In the following section we investigate to what extent the overestimation of LAI for the boreal forests may be responsible for the overestimation of GPP. 

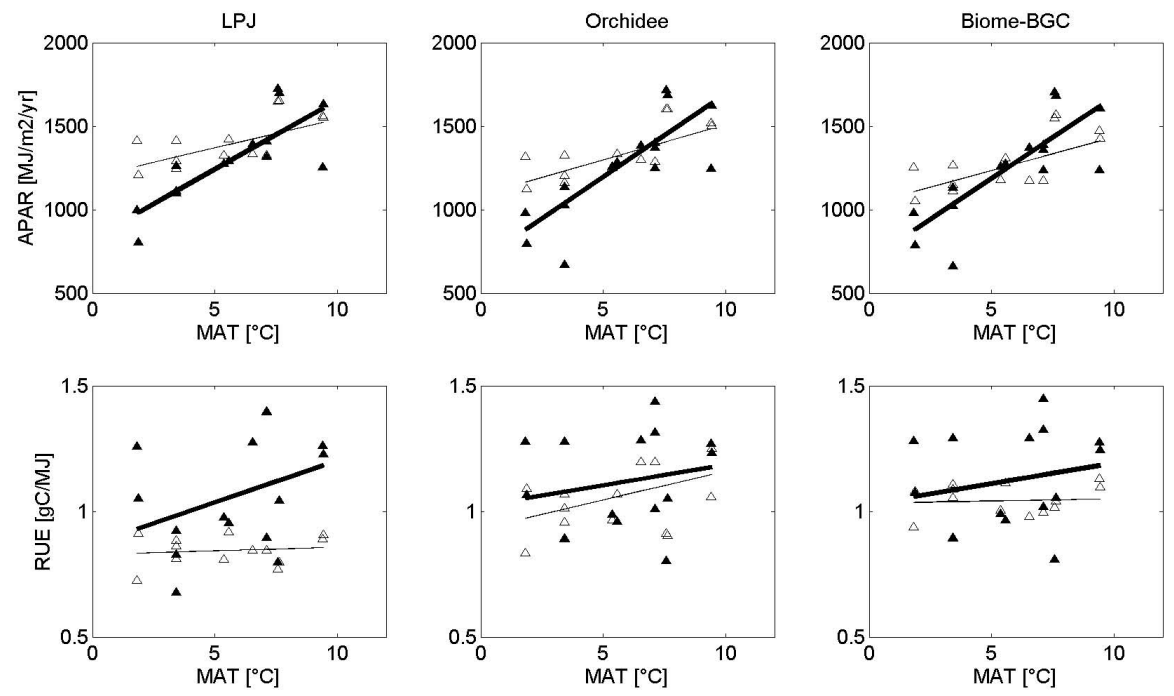

Fig. 5. Site (filled markers) and modelled (open markers) trends of APAR and RUE along the mean annual temperature gradient for boreal and temperate coniferous forests. Bold line: trend of site values; thin line: trend of modelled values. The trend of site values can differ among models since the model specific simulated seasonal pattern of LAI was used to estimate APAR and consequently RUE.

Table 2. Trends of APAR and RUE along MAT for boreal and temperate evergreen needleleaf forests.

\begin{tabular}{|c|c|c|c|c|}
\hline & \multicolumn{2}{|c|}{ Slope APAR vs MAT $\left[\mathrm{MJ} /{ }^{\circ} \mathrm{C}\right]$} & \multicolumn{2}{|c|}{ Slope RUE vs MAT $\left[\mathrm{gC} / \mathrm{MJ} /{ }^{\circ} \mathrm{C}\right]$} \\
\hline & Modelled & $\begin{array}{l}\text { Estimated } \\
\text { from Obser- } \\
\text { par vations }\end{array}$ & Modelled & $\begin{array}{l}\text { Estimated } \\
\text { from Obser- } \\
\text { vations }\end{array}$ \\
\hline LPJ & 34.58 & 82.78 & 0.003 & 0.033 \\
\hline Orchidee & 42.11 & 99.65 & 0.016 & 0.023 \\
\hline Biome-BGC & 40.1 & 97.87 & 0.002 & 0.017 \\
\hline
\end{tabular}

\subsection{Decomposing GPP into APAR and RUE}

In the following section we investigate to what extent the overestimation of LAI for the boreal forests may be responsible for the overestimation of GPP.

Figure 5 shows APAR and RUE along MAT for boreal and temperate conifers. Because the simulated seasonal pattern of LAI was used to estimate site APAR, a site APAR for each model is presented (see Sect. 2.3). Site and modelled APAR increase with MAT and are correlated significantly (Pearson's correlation, $\mathrm{p}<0.05$ ), but the site APARs increase more steeply with MAT (see also Table 2). As shown above, the models cannot reproduce the increase of fAPAR (i.e. increase of LAI) from boreal to temperate so that their slope of APAR vs MAT simply represents increasing radiation, while the larger observed slope is due to additionally increasing fAPAR.

Despite considerable scatter there is a trend of site RUE to increase with MAT which is only reproduced by the Orchidee model but the Pearson's correlation between MAT and RUE is not significant in both cases. The trend of increasing RUE in observed data from boreal to temperate regions is confirmed by an independent study using remotely sensed fAPAR and in-situ measured radiation (Jung, unpublished). Rising RUE may result from more favourable temperature conditions for photosynthesis or due to increasing rubisco concentrations in the needles as nitrogen becomes more available. The latter factor is supported by data from Wright et al. (2004) that show larger concentrations of nitrogen per unit of leaf area in temperate than in boreal biomes. The Orchidee model shows increasing RUE with MAT likely because different optimum temperatures are assigned for boreal and temperate coniferous trees.

Site APAR and RUE for LPJ are different than "site" for Orchidee and Biome-BGC, the latter two being almost identical (Fig. 5). This difference can only result from different seasonal patterns of LAI. The assumption in LPJ that leaf area is constant over the year for evergreens seems to have a significant effect. Modelling small increases of fAPAR during summer (fresh needles) when radiation is high seems to 

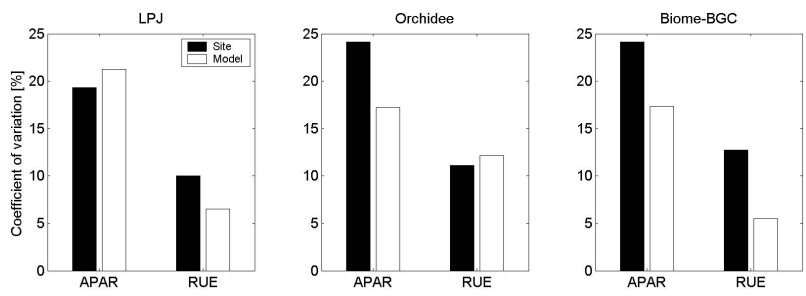

Fig. 6. Coefficient of variation (standard deviation/mean) of APAR and RUE for boreal and temperate coniferous forests based on site and modelled data. The discrepancy of LPJ site data with site data based on Orchidee and Biome-BGC results from the assumption of constant leaf area over the year (see text).

be important for the magnitude of absorbed radiation. We showed above that both site APAR and RUE increase more strongly with MAT than predicted by the models. The question is which of the two factors has the larger effect in explaining increasing GPP from boreal to temperate forests. Since GPP is the product of APAR and RUE, the answer to the question can be inferred from the coefficient of variation (standard deviation divided by mean) of both factors. The factor that varies more also controls more the variations of GPP. Site data and the models agree that changes of APAR is the dominant factor that explains increasing GPP from boreal to temperate coniferous forests in Europe, while changes of RUE are of secondary importance (Fig. 6). The variation of APAR is more than twice as high as the variation of RUE and it is therefore likely that the data-model mismatch for boreal conifer forests is primarily caused by overestimating LAI. Since both, foliage area as well as RUE is related to nitrogen availability the implementation or improvement of a nitrogen cycle in the models would likely enhance the model's performance. In fact, Magnani et al. (2007) have shown that the relationship of forest GPP along mean annual temperature in Europe is concomitant on nitrogen availability.

Bias of GPP simulations along large environmental gradients is likely also related to assumptions made by representing vegetation using broad categories of plant functional types (PFTs). Many important plant traits (e.g. leaf nitrogen concentration, specific leaf area, leaf longevity) that control biogeochemical cycling are represented as constant PFT specific parameters in the models. These traits are known to vary within and between PFTs, and systematically along environmental gradients (e.g. Reich and Oleksyn, 2004; Wright et al., 2005; Wright et al., 2004; Wright et al., 2006). Accounting for the variation of vegetation properties which are currently kept constant in the models would certainly improve their predictability. Using simple empirical relationships with climate have not improved simulations successfully (e.g. White et al., 2000). However, approaches of understanding the variation and co-variation of key plant traits using the theory of optimality in ecosystems regarding the use of resources (mainly water, light, nitrogen) has been promising (e.g. Anten, 2002; Anten, 2005; Hikosaka, 2005; Shipley et al., 2006). This concept is attractive for global prognostic ecosystem models but there is still too little known regarding when optimality applies, what is optimised and how, and the respective time scale.

\section{Conclusions}

We estimate the root mean square error of prediction (RMSE) over all forest sites to be in the order of $420 \mathrm{gC} / \mathrm{m} 2 / \mathrm{yr}$ $(\sim 30 \%)$ for all three models. In terms of absolute simulated GPP values this uncertainty range may be considered to be within the joint uncertainty resulting from input driver data and eddy-covariance based GPP estimates. However, we find systematic biases in the model simulations along the climatic gradient from the boreal to the Mediterranean region.

Based on a simple method that decomposes GPP into APAR and RUE, we conclude that the tested models consistently overestimate GPP for boreal forests due to the tendency of the models to simulating too high LAI in this region. Due to general N-limitation in the boreal zone, accounting explicitly for nitrogen limitation should reduce the simulated LAI and therefore improve the model performance for the boreal zone. The method of GPP decomposition may be useful for future evaluations of large scale carbon cycle simulations based on global measurement databases of GPP that include also LAI data.

The tendency of all three models to underestimate GPP in the water limited part of Europe indicates issues of model structure regarding their soil hydrology. However, this pattern is likely, at least partly, a consequence of questionable meteorological input data over this region.

We have undertaken an evaluation of global ecosystem models on a continental scale, including many sites and covering large climatic gradients. Such effort has been neglected in the past but is necessary to identify model biases along environmental gradients or to gain confidence in simulations. Large scale data-model comparison studies need to be fostered by the community in the future.

Acknowledgements. This study was conducted in the frame of CARBOEUROPE-Integrated Project "Assessment of the European Carbon Balance" (GOCE-CT-2003-505572). Soenke Zaehle was supported by a Greencycles MarieCurie fellowship (MRTNCT-2004-512464). S. Luyssaert was funded by the Research Foundation - Flanders (FWO-Vlaanderen) with a post-doctoral fellowship and a research grant. M. Jung was partly supported by a stipend of the German Academic Exchange Service (DAAD). Guerric le Maire was supported by a Region Ile-de-France postdoctoral fellowship.

Edited by: T. Laurila 


\section{References}

Anten, N. P. R.: Evolutionarily stable leaf area production in plant populations, J. Theoretical Biol., 217(1), 15-32, 2002.

Anten, N. P. R.: Optimal photosynthetic characteristics of individual plants in vegetation stands and implications for species coexistence, Annals of Botany (London), 95(3), 497-508, 2005.

Bondeau, A., Kicklighter, D. W., and Kaduk, J.: Comparing global models of terrestrial net primary productivity (NPP): importance of vegetation structure on seasonal NPP estimates, Global Change Biol., 5, 35-45, 1999.

Breda, N.: Ground-based measurements of leaf area index: a review of methods, instruments and current controversies, J. Experimental Botany, 54(392), 2403-2417, 2003.

Churkina, G., Tenhunen, J., Thornton, P., Falge, E. M., Elbers, J. A., Erhard, M., Grunwald, T., Kowalski, A. S., Rannik, U., and Sprinz, D.: Analyzing the ecosystem carbon dynamics of four European coniferous forests using a biogeochemistry model, Ecosystems, 6(2), 168-184, 2003.

Cowling, S. A. and Field, C. B.: Environmental control of leaf area production: Implications for vegetation and land-surface modeling, Global Biogeochem. Cycles, 17(1), p. 14, 2003.

Cramer, W., Kicklighter, D. W., Bondeau, A., Moore, B., Churkina, C., Nemry, B., Ruimy, A., and Schloss, A. L.: Comparing global models of terrestrial net primary productivity (NPP): overview and key results, Global Change Biol., 5, 1-15, 1999.

Feser, F., Weisse, R., and von Storch, H.: Multi-decadal Atmospheric Modeling for Europe Yields Multi-purpose Data, EOS Transactions, 82, 305-310, 2001.

Hikosaka, K.: Leaf Canopy as a Dynamic System: Ecophysiology and Optimality in Leaf Turnover, Ann. Bot., 95(3), 521-533, doi:10.1093/aob/mci050, 2005.

IGBP-DIS: Global Soil Data Products CD-ROM. Global Soil Data Task 2000.

Jacob, D. and Podzun, R.: Sensitivity studies with the regional climate model REMO, Meteorol. Atmos. Phys., 63(1-2), 119-129, 1997.

Jung, M., Vetter, M., Herold, M., Churkina, G., Reichstein, M., Zaehle, S., Cias, P., Viovy, N., Bondeau, A., Chen, Y., Trusilova, K., Feser, F., and Heimann, M.: Uncertainties of modelling GPP over Europe: A systematic study on the effects of using different drivers and terrestrial biosphere models, Global Biogeochem. Cycles, accepted, 2007.

Kalnay, E., Kanamitsu, M., Kistler, R., Collins, W., Deaven, D., Gandin, L., Iredell, M., Saha, S., White, G., Woollen, J., Zhu, Y., Chelliah, M., Ebisuzaki, W., Higgins, W., Janowiak, J., Mo, K. C., Ropelewski, C., Wang, J., Leetmaa, A., Reynolds, R., Jenne, R., and Joseph, D.: The NCEP/NCAR 40-year reanalysis project, Bull. Am. Meteorol. Soc., 77(3), 437-471, 1996.

Krinner, G., Viovy, N., de Noblet-Ducoudre, N., Ogee, J., Polcher, J., Friedlingstein, P., Ciais, P., Sitch, S., and Prentice, I. C.: A dynamic global vegetation model for studies of the coupled atmosphere-biosphere system, Global Biogeochem. Cycles, 19(1), 33 pp., 2005.

Kucharik, C. J. Barford, C. C., El Maayar, M., Wofsy, S. C., Monson, R. K., and Baldocchi, D. D.: A multiyear evaluation of a Dynamic Global Vegetation Model at three AmeriFlux forest sites: Vegetation structure, phenology, soil temperature, and $\mathrm{CO} 2$ and H2O vapor exchange, Ecol. Model. 196(1-2), 1-3, 20061.

Luyssaert, S., Inglima, I., Jung, M., Reichstein, M., Papale, D.,
Piao, S., Schulze, E.-D., Wingate, L., Matteucci, G., Aubinet, M., Beer, C., Bernhofer, C., Black, K. G., Bonal, D., Chambers, J., Ciais, P., Davis, K. J., Delucia, E. H., Dolman, A., Don, A., Gielen, B., Grace, J., Granier, A., Grelle, A., Griffis, T., Grnwald, T., Guidolotti, G., Hanson, P., Harding, R., Hollinger, D., Kolari, P., Kruijt, B., Kutsch, W., Lagergren, F., Laurila, T., Law, B., Le Maire, G., Lindroth, A., Magnani, F., Marek, M., Mateus, J., Migliavacca, M., Misson, L., Montagnani, L., Moncrieff, J., Moors, E., Munger, J. W., Nikinmaa, E., Loustau, D., Pita, G., Rebmann, C., Richardson, A. D., Roupsard, O., Saigusa, N., Sanz, M., Seufert, G., Soerensen, L., Tang, J., Valentini, R., Vesala, T., and Janssens, I. A.: The CO2-balance of boreal, temperate and tropical forests derived from a global database, Global Change Biol., accepted, 2007.

Magnani, F. Mencuccini, M., Borghetti, M., Berbigier, P., Berninger, F., Delzon, S., Grelle, A., Hari, P., Jarvis, P. G., Kolari, P., Kowalski, A. S., Lankreijer, H., Law, B. E., Lindroth, A., Loustau, D., Manca, G., Moncrieff, J. B., Rayment, M., Tedeschi, V., Valentini, R., and Grace, J.: The human footprint in the carbon cycle of temperate and boreal forests, Nature, 447(7146), 849-851, 2007.

McGuire, A. D., Sitch, S., Clein, J. S., Dargaville, R., Esser, G., Foley, J., Heimann, M., Joos, F., Kaplan, J., Kicklighter, D. W., Meier, R. A., Melillo, J. M., Moore, B., Prentice, I. C., Ramankutty, N., Reichenau, T., Schloss, A., Tian, H., Williams, L. J., and Wittenberg, U.: Carbon balance of the terrestrial biosphere in the twentieth century: Analyses of $\mathrm{CO} 2$, climate and land use effects with four process-based ecosystem models, Global Biogeochem. Cycles, 15(1), 183-206, 2001.

Moorcroft, P. R.: How close are we to a predictive science of the biosphere?, Trends in Ecology \& Evolution, 21(7), 400-407, 2006.

Morales, P., Sykes, M. T., Prentice, I. C., Smith, P., Smith, B., Bugmann, H., Zierl, B., Friedlingstein, P., Viovy, N., Sabate, S., Sanchez, A., Pla, E., Gracia, C. A., Sitch, S., Arneth, A., and Ogee, J.: Comparing and evaluating process-based ecosystem model predictions of carbon and water fluxes in major European forest biomes, Global Change Biol., 11(12), 2211-2233, 2005.

Reich, P. B. and Oleksyn, J.: Global patterns of plant leaf N and P in relation to temperature and latitude. Proceedings of the National Academy of Sciences of the United States of America, 101(30), 11 001-11 006, 2004.

Reichstein, M., Falge, E., Baldocchi, D., Papale, D., Aubinet, M., Berbigier, P., Bernhofer, C., Buchmann, N., Gilmanov, T., Granier, A., Grunwald, T., Havrankova, K., Ilvesniemi, H., Janous, D., Knohl, A., Laurila, T., Lohila, A., Loustau, D., Matteucci, G., Meyers, T., Miglietta, F., Ourcival, J. M., Pumpanen, J., Rambal, S., Rotenberg, E., Sanz, M., Tenhunen, J., Seufert, G., Vaccari, F., Vesala, T., Yakir, D., and Valentini, R.: On the separation of net ecosystem exchange into assimilation and ecosystem respiration: review and improved algorithm, Global Change Biol., 11(9), 1424-1439, 2005.

Reichstein, M., Papale, D., Valentini, R., Aubinet, M., Bernhofer, C., Knohl, A., Laurila, T., Lindroth, A., Moors, E., Pilegaard, K., and Seufert, G.: Determinants of terrestrial ecosystem carbon balance inferred from European eddy covariance flux sites, Geophys. Res. Lett. 34, 5 pp., doi:10.1029/2006GL027880, 2007.

Ruimy, A., Kergoat, L. and Bondeau, A.: Comparing global models of terrestrial net primary productivity (NPP): analysis of differ- 
ences in light absorption and light-use efficiency, Global Change Biol., 5, 56-64, 1999.

Scurlock, J. M. O., Cramer, W., Olson, R. J., Parton, W. J., and Prince, S. D.: Terrestrial NPP: Toward a consistent data set for global model evaluation, Ecol. Appl., 9(3), 913-919, 1999.

Shipley, B., Lechoweicz, M. J., Wright, I., and Reich, P. B.: Fundamental trade-offs generating the worldwide leaf economics spectrum, Ecology, 87(3), 535-541, 2006.

Sitch, S., Smith, B., Prentice, I. C., Arneth, A., Bondeau, A., Cramer, W., Kaplan, J. O., Levis, S., Lucht, W., Sykes, M. T., Thonicke, K., and Venevsky, S.: Evaluation of ecosystem dynamics, plant geography and terrestrial carbon cycling in the LPJ dynamic global vegetation model, Global Change Biol., 9(2), 161-185, 2003.

Thornton, P.: Regional Ecosystem Simulation: Combining Surfaceand Satellite-Based Observations to Study Linkages between Terrestrial Energy and Mass Budgets. PhD Thesis, University of Montana, Missoula, 1998.

Thornton, P.: Modeling and measuring the effects of disturbance history and climate on carbon and water budgets in evergreen needleleaf forests, Agr. Forest Meteorol., 113, 185-222, 2002.
Vetter, M., Churkina, G., Bondeau, A., Chen, Y., Ciais, P., Feser, F., Freibauer, A., Geyer, R., Heimann, M., Jones, C., Jung, M., Papale, D., Reichstein, M., Tenhunen, J., Tomelleri, E., Viovy, N., and Zaehle, S: Analyzing the causes and spatial pattern of the European 2003 carbon flux anomaly in Europe using seven models, Biogeosciences Discuss., 4, 1201-1240, 2007, http://www.biogeosciences-discuss.net/4/1201/2007/.

White, A., Thornton, P., Running, S., and Nemani, R.: Parameterization and sensitivity analysis of the Biome-BGC terrestrial ecosystem model: Net primary production controls, Earth Interactions, 4(3), 1-85, 2000.

Wright, I. J., Reich, P. B., Cornelissen, J. H. C., Falster, D. S., Groom, P. K., Hikosaka, K., Lee, W., Lusk, C. H., Niinemets, U., Oleksyn, J., Osada, N., Poorter, H., Warton, D. I., and Westoby, M.: Modulation of leaf economic traits and trait relationships by climate, Global Ecol. Biogeogr., 14(5), 411-421, 2005.

Wright, I. J., Global Ecology and Biogeography et al.: The worldwide leaf economics spectrum, Nature, 428(6985), 821-827, 2004.

Wright, J. P., Global Ecology and Biogeography et al.: Conventional functional classification schemes underestimate the relationship with ecosystem functioning, Ecol. Lett., 9(2), 111-120, 2006.

Zaehle, S., Sitch, S., Smith, B., and Hatterman, F.: Effects of parameter uncertainties on the modeling of terrestrial biosphere dynamics, Global Biogeochem. Cycles, 19(3), 18 pp., 2005. 